\title{
MULTIYEAR AEROSOL STUDY BASED ON LIDAR\&SUNPHOTOMETER MEASUREMENTS IN ROMANIA
}

\author{
Anca Nemuc ${ }^{1 *}$, Ioannis Binietoglou ${ }^{1}$, Simona Andrei ${ }^{1}$, Alexandru Dandocsi ${ }^{1,2}$, Horatiu Stefanie ${ }^{1,3,4}$
}

\author{
${ }^{I}$ National Institute of Research and Development for Optoelectronics INOE, Bucharest-Magurele, \\ Romania, *Email: anca@inoe.ro \\ ${ }^{2}$ University Politehnica of Bucharest, Faculty of Applied Sciences, Bucharest, Romania \\ 3 “Babeș-Bolyai" University of Cluj-Napoca, Faculty of Environmental Science and Engineering, Cluj- \\ Napoca, Romania \\ ${ }^{4}$ University of Bucharest, Faculty of Physics, P.O.BOX MG-11, Magurele, Bucharest, Romania
}

\begin{abstract}
This observational study focused on three-years time-averaged data set (January 2012-2015). An investigation of long-term trends was performed on two different data sets derived from active and passive remote sensing measurements in Magurele, Romania.

Measurements of sun photometer aerosol optical depth (AOD) at $500 \mathrm{~nm}$ and $340 \mathrm{~nm}$ show the mean values of $0.230 \pm 0.118$ and $0.398 \pm 0.185$, respectively. The lidar AOD at 532 and $355 \mathrm{~nm}$ has a mean of $0.271 \pm .0 .164$ and $0.472 \pm 0.165$ respectively. The highest seasonal mean value was measured by the lidar during the summer of 2014 while the lowest seasonal value was measured by the sunphotometer in February 2012.

The origin of atmospheric aerosols has been analyzed using both backtajectories of Hysplit and Circulation Type Classification (CTCs) methods.
\end{abstract}

\section{INTRODUCTION}

Despite of the GCMs (General Circulation Model) improvements in the last years, aerosols are still not well captured, therefore long term observations are essential to address the questions of global climate changes.

EARLINET (European Aerosol Lidar Network) started in 2000 a coordinated research strategy to quantitatively address the complex aerosolclimate problem. Many climatological studies, Saharan dust outbreaks, volcanic eruptions, biomass burning layers have been documented for model evaluation and satellite data validation and integration [1]. The EARLINET procedures ensure instrument standardization and consistent retrievals within the network [2].

Detailed analyses of high-quality observations of aerosol microphysical and optical properties from long-term AERONET (Aerosol Robotic Network) (http://aeronet.gsfc.nasa.gov/) monitoring sites can yield a complete characterization of aerosol optical effects for a wide range of applications climatology of atmospheric aerosols [3]. In order to establish the origin of atmospheric aerosols two classical approaches (Lagrangian and Eulerian) are generally used. One is the Lagrangian analysis of back trajectories using Hysplit model [4]. Second, the Eulerian approach can be used via Circulation Type Classification methods based on synoptic fields at one time instant [5].

The methodology used for analysis of lidar measurements and sunphotometer during 2012January 2015 near Bucharest, Romania, along with an estimation of the aerosol types influence during this time is provided in the next sections.

\section{METHODOLOGY}

The multiwavelenth Raman Lidar (RALI) at INOE has been submitting data to EARLINET since 2010, but major upgrades to include calibrated depolarization were only performed since 2012. Technical details are described in [6]. The climatology data used in this study was measured in the frame of EARLINET, between January 2012 and 2015, containing 162 lidar measurements of aerosol extinction and backscatter coefficients at 355 and $532 \mathrm{~nm}$.

The sun-photometer is operational in the AERONET since July 2007 and provides direct solar irradiance measurements at 8 different 
wavelengths from UV to near IR (340, 380, 440, $500,675,870,1020$ and $1640 \mathrm{~nm}$ ) and further the aerosol optical depth (AOD) at each wavelength from the surface to the top of the atmosphere [7]. Monthly variation of the AOD is described based on the sunphotometer data Bucharest_Inoe site and on RALI measurements performed every Monday and Thursday sunset time, with one hour average. Both instruments are located in Magurele, $5 \mathrm{~km}$ South of Bucharest (45.35 N, 26.03 E). Standard deviation values are reported as errors of the mean values to provide information about the typical aerosol load and its variability.

To identify the connections between large scale circulation patterns and the short-to-long-range aerosol transport, the Wetter Lagen Klassifikation (WLKC733) developed within "COST733Action" [8] has been used. This is an automated thresholdbased catalog derived from the "Objektive Wetterlagenklassifikation-OWLK" classification developed at German Weather Service [9]. It uses information from three tropospheric levels: 925, 700 and $500 \mathrm{hPa}$, and information regarding water content over the entire tropospheric column. Geopotential fields at $925 \mathrm{hPa}$ and $500 \mathrm{hPa}$ are
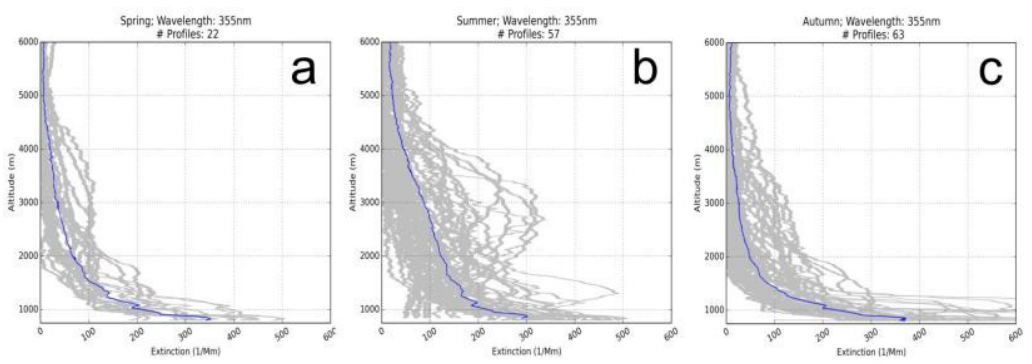

Soring: Wavelengt: 53 : Fortiles 23
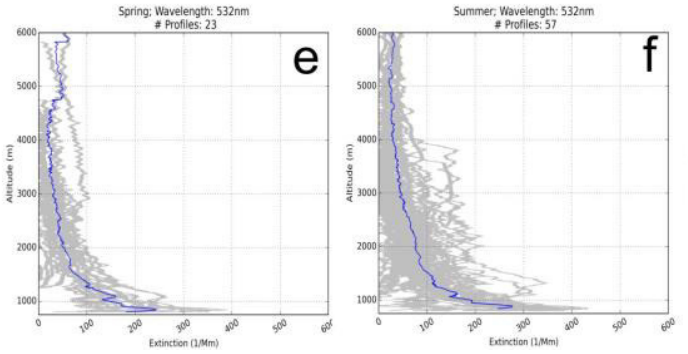

used to establish the cyclonicity or anticyclonicity, while the wind at $700 \mathrm{hPa}$ is used to establish the dominant flow direction. Because of the increased number of inputs the catalog generates 40 circulation types.

According to this catalog, for each time step (day in this study) - a certain type of circulation was assigned, as the most predominant ones are: NE (Nord East-Moldova, Ukraine, Russia), SE (Black Sea-South East, Turkey, Caucasus Region), SW (South West- from the Balkans, Mediterranean area, Sahara), NW (North West-Central Europe).

\section{RESULTS}

\section{Seasonal variation of extinction profiles}

The occurrence of strong, elevated aerosol layers can best be seen in the summer profiles (Fig.1 panels $b$ and $f$ ). Large extinction coefficients occur frequently up to $4-5 \mathrm{~km}$ in summer and autumn (Fig.1 panels b,c,f,g). In contrast, the winter profiles mostly show aerosol below $2 \mathrm{~km}$; only in a few profiles we observe values large values above this height (Fig.1 panels $\mathrm{d}$ and $\mathrm{h}$ ).
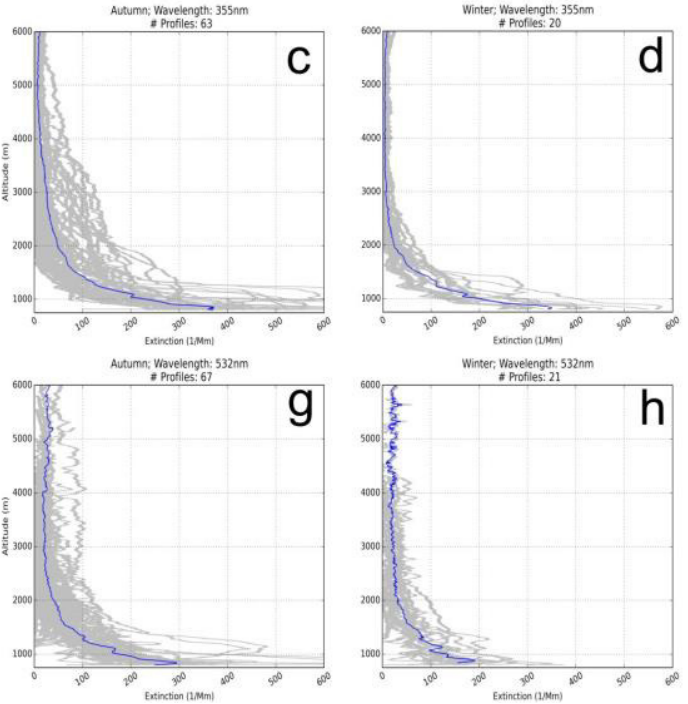

Fig. 1 Extinction coefficient profiles in grey, grouped into season (a,e -spring; $\boldsymbol{b}, \boldsymbol{f}$-summer; $\boldsymbol{c}, \boldsymbol{g}$-fall; $\boldsymbol{d}, \boldsymbol{h}$-winter), at $355 \mathrm{~nm}$ (upper panel), $532 \mathrm{~nm}$ (lower panel), mean profiles (dark blue) derived from RALI measurements in Magurele (93m a.s.l.). Used are all EALINET climatology data from 2012 to January 2015

\section{Occurrences of aerosol types}

In Fig.2 is presented the distribution of the occurrence of different aerosol types as detected in different layers by RALI and is confirmed by complementary tools (HYSPLIT, MODIS fire maps), separated for the four seasons. 
The assessment, carried out for the entire data set (multi-annual evaluation) and seasonal evaluation (Fig.2), emphasized the presence of aerosols within three main layers. The first one, between 0.5 and about $2 \mathrm{~km}$, can be assimilated with the PBL (Planetary Boundary Layer). Its height varies seasonally, the upper limit being at an altitude of $1.36 \mathrm{~km}$ during wintertime and $2.09 \mathrm{~km}$ during summertime. The second layer (between 2 and 4 $\mathrm{km})$ has been detected in $44 \%$ of the analyzed cases, and the third layer (between 4 and $6 \mathrm{~km}$ ) was identified only in $8 \%$ of cases.

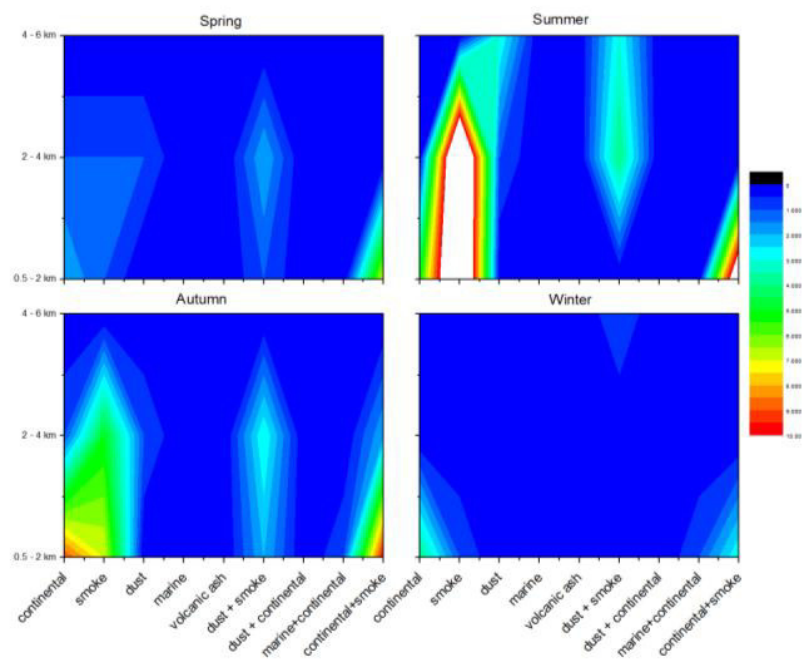

Fig. 2 Multiannual and seasonal distribution of aerosol types in different layer $(0.5-2 \mathrm{Km} ; 2-4 \mathrm{Km} ; 4-6 \mathrm{~km})$ as measured at Magurele

Occasionally (1case), the presence of a fourth layer has been noticed at heights of over $10 \mathrm{~km}$. This particular event was due to trans-continental $\&$ trans-oceanic transport of mineral particles from desert areas of Asia (Gobi desert in our case), following intense storms ten days earlier.

\section{Observations of atmospheric aerosol columnar}

AOD values from extinction profiles (at $532 \mathrm{~nm}$ and $355 \mathrm{~nm}$ ) have been calculated from the measured ones starting at $850 \mathrm{~m}$ while for the lowest PBL part an exponential decay have been considered in order to eliminate the bias related to different altitude ranges measured by the two instruments. The AOD wavelength dependency of the two RALI wavelengths $532 \mathrm{~nm}$ and $355 \mathrm{~nm}$ can be seen in the average values $(0.271 \pm 0.164$, and $0.472 \pm 0.165$ respectively) as well as in the monthly and seasonal variation of the AOD (Fig.
3). The AOD decreases with increasing wavelength.

Optical properties were analyzed from January 2012 to January 2015. During this period 162 days of measurements were retrieved from AERONET level 2.0 (01.2012-03.2014) and level 1.5 data (03.2014-01.2015). There are gaps in the data of about one month yearly due to the system calibrations and upgrade.

AOD monthly values range from 0.03 to 0.6 (500 $\mathrm{nm}$ sunphotometer, $532 \mathrm{~nm}$ lidar) and from 0.12 to 0.45 (340nm sunphotometer, $355 \mathrm{~nm}$ lidar) respectively. The values from May to September (spring to late summer) are slightly higher than the winter months (October to February). The lowest AOD occurs in February, while the maximum is reached in August.

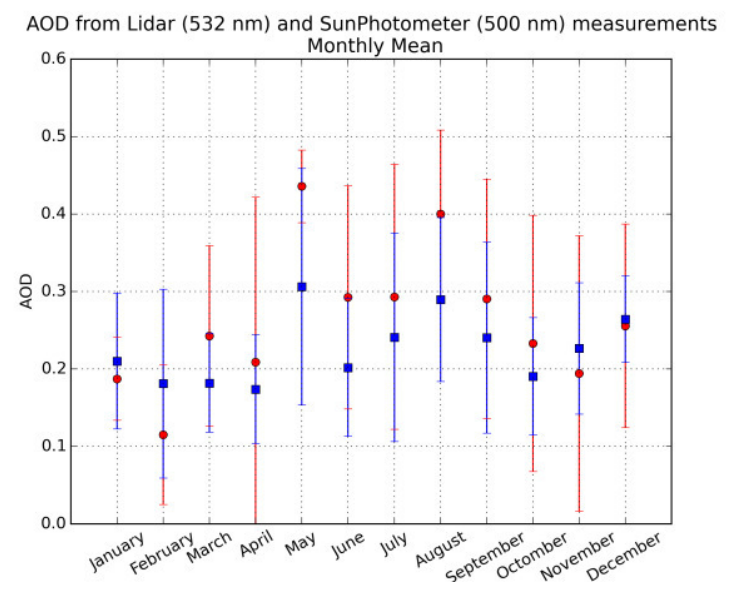

Fig. 3 Monthly mean and uncertainty of AODs from lidar in red (532 $\mathrm{nm})$ and sunphotometer in blue (500nm). The error bars show the variability within the mean

The monthly means of the two instruments match well with each other, with highest values in August, and the minimum AOD of both instruments in winter, indicating that these values are credible. However, on a monthly scale some differences can be seen: some, such as that AERONET encounters absolute minima in April while RALI has it in February. Large differences between the two instruments in May, June and August can be explained by the large uncertainties. This data points to singular high AOD events moving the mean AOD to larger or lower values. These differences could also arise from the different sampling times (during night lidar and daytime-sunphotometer). 


\section{Circulation patterns}

The predominant sectors identified as the origin of the air masses monthly averages are represented in Fig. 4. It can be noted the predominance of the circulation from the NW (bringing mainly continental polluted aerosol from Central Europe) during December and February and also the frequent SW circulation from June to October (mostly linked with Saharan dust intrusions and biomass burning influence).

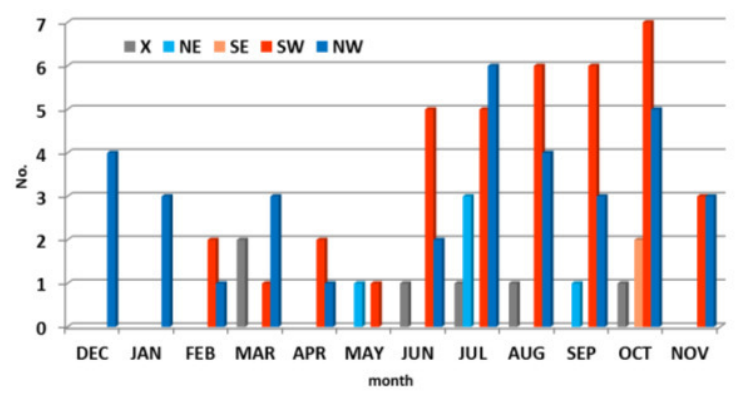

Fig. 4 Monthly distribution of Circulation types- main predominant directions January 2012 - 2015

\section{CONCLUSIONS}

To characterize the three years aerosol columnar properties and to quantify the contribution of different aerosol types we used lidar and sunphotometer data along with CTCs analysis.

AODs at $355(340) \mathrm{nm}$ and $532(500) \mathrm{nm}$ are characterized by a wide range of values from 0.03 to 0.6 and from 0.15 to 0.45 respectively, as shown by the measurements above Magurele, Romania. Although some discrepancies exist between the two datasets monthly averages of AOD evidence a seasonal behavior: higher AOD values are mainly observed during summer months while the minimum ones are in winter.

We observed elevated aerosol layers during summer and fall as shown by the measured lidar profiles with high extinction coefficients occurring frequently up to $4-5 \mathrm{~km}$. The averaged seasonal CTCs highlighted the long-range transport of mixed aerosol: dust from desert regions and biomass burning from Ukraine and Greece (summer and fall). The local sources seem to be the only ones contributing to the aerosol load during the winter since we could see mostly aerosol below $1.2 \mathrm{~km}$.

\section{ACKNOWLEDGEMENT}

This work has been supported by grants of the STARESA Programme Project No. 38/2012- CAPESA and Project No.55/2013- CARESSE.

MODIS active fire products were supplied by Fire Information for Resource Management System FIRMS (NASA Information for Research Management System) at the University of Maryland. The authors gratefully acknowledge the NOAA Air Resources Laboratory (ARL) for the provision of the HYSPLIT transport model and/or READY website (http://www.arl.noaa.gov/ready.html ).

\section{REFERENCES}

[1]Pappalardo, G., et. al. , 2014: EARLINET: towards an advanced sustainable European aerosol lidar network, Atmos. Meas. Tech., 7, 2389-2409, doi:10.5194/amt-7-2389-2014.

[2]Böckmann, C. et al., 2004: “Aerosol lidar intercomparison in the framework of the EARLINET project. 2. Aerosol backscatter algorithms", Applied Optics, 43, pp. 977-989.

[3]Schafer, J. S. et al., 2008: Characterization of the optical properties of atmospheric aerosols in Amazônia from long-term AERONET monitoring (1993-1995 and 1999-2006), J. Geophys. Res., 113 D04204.

[4]Toledano, C. et al., 2009: Airmass Classification and Analysis of Aerosol Types at El Arenosillo (Spain). J. Appl. Meteor. Climatol., 48, 962-981.

[5]Cahynová M. and Huth R., 2010: Circulation vs. climatic changes over the Czech Republic: a comprehensive study based on the COST733 database of atmospheric circulation classifications, Phys. Chem. Earth, 35, 422-428.

[6] Nemuc, A. et al., 2013: Assessment of aerosol's mass concentrations from measured linear particle depolarization ratio (vertically resolved) and simulations, Atmos. Meas. Tech., 6, 3243-3255.

[7]Dubovik, O. et al., 2000: Accuracy assessments of aerosol optical properties retrieved from Aerosol Robotic Network (AERONET) Sun and sky radiance measurements, J. Geophys. Res., 105, 9791-9806.

[8]Philipp, A. et al., 2014: Development and comparison of circulation type classifications using the COST 733 dataset and software, Int. J. Climatol., DOI: 10.1002/joc.3920.

[9]Bissolli D. and Dittmann E., 2001: The objective weather type classification of the German Weather Service and its possibilities of application to environmental and meteorological investigations, Meteorologische Zeitschrift, 10(4), 253-260. 